\title{
UNIVERSITYOF
}

FORWARD

THINKING

WESTMINSTER用

WestminsterResearch

http://www.westminster.ac.uk/westminsterresearch

Technical considerations for the generation of novel

pseudotyped viruses

King, B., Temperton, N.J., Grehan, K., Scott, S.D., Wright, E., Tarr, A.W., Daly, J.M.

This is an author's accepted manuscript of an article published in Future Virology, 11 (1), pp. 47-59, 2016. The final definitive version is available online at:

http://www.futuremedicine.com/doi/full/10.2217/fvl.15.106

The WestminsterResearch online digital archive at the University of Westminster aims to make the research output of the University available to a wider audience. Copyright and Moral Rights remain with the authors and/or copyright owners.

Whilst further distribution of specific materials from within this archive is forbidden, you may freely distribute the URL of WestminsterResearch: ((http://westminsterresearch.wmin.ac.uk/)).

In case of abuse or copyright appearing without permission e-mail repository@westminster.ac.uk 


\section{Technical considerations for the generation of novel}

\section{pseudotyped viruses}

Barnabas King ${ }^{1,2}$, Nigel J Temperton 3 , Keith Grehan ${ }^{3}$, Simon Scott ${ }^{3}$, Edward Wright ${ }^{4}$, Alexander W. Tarr1,2, Janet M Daly5

${ }^{1}$ School of Life Sciences and ${ }^{2}$ NIHR Biomedical Research Unit in Gastrointestinal and Liver Diseases, Queen's Medical Centre, University of Nottingham, Nottingham NG7 2UH. ${ }^{3}$ Viral Pseudotype Unit (Medway), School of Pharmacy, Anson Building, Central Avenue, Chatham Maritime, Chatham, Kent, ME4 4TB, UK

${ }^{4}$ Viral Pseudotype Unit (Fitzrovia), Faculty of Science and Technology, University of Westminster, 115 New Cavendish Street, London, W1W 6UW, UK ${ }^{5}$ School of Veterinary Medicine and Science, University of Nottingham, Sutton Bonington Campus, Leicestershire, LE12 5RD, UK

\section{Keywords}

Pseudotyped virus, pseudotypes, pseudoparticles, envelope glycoproteins

\section{Future Perspectives}

The use of pseudotyped viruses has historically been limited to a small number of readily tractable viruses. However, the flexibility of pseudotyped viruses makes them attractive as safe surrogates for enveloped viruses requiring high bio-containment, for use in serological screening, assessing vaccine efficacy, targeted gene transduction, virus entry inhibition and receptor usage studies. Through the development of more standardized protocols, a broader range of reporter genes and backbone viruses, virus pseudotyping will become a central and powerful technique in the study and treatment of enveloped viruses. 


\title{
Executive Summary
}

- A pseudotyped virus (PV) is a single-round infectious virus particle with an envelope protein originating from a different virus

- PVs of highly pathogenic viruses are an important, safe tool for basic virological studies

- PVs have been used to identify virus receptors, potential antiviral compounds and assess specific antibody responses

- The common methodologies employed to generate novel PVs are described

- Generation of novel PVs involves numerous technical considerations which are discussed

\begin{abstract}
A pseudotyped virus (PV) is a virus particle with an envelope protein originating from a different virus. The ability to dictate which envelope proteins are expressed on the surface has made pseudotyping an important tool for basic virological studies such as determining the cellular targets of the envelope protein of the virus as well as identification of potential antiviral compounds and measuring specific antibody responses. In this review, we describe the common methodologies employed to generate PVs, with a focus on approaches to improve the efficacy of PV generation.
\end{abstract}




\section{What are pseudotyped viruses?}

In 1911, Peyton Rous published the first report of a non-cellular, filterable agent that could produce cancer - a sarcoma of chickens [1]. This agent was later named the Rous sarcoma virus (RSV) and was used to generate the first virus pseudotypes [2].

Rubin and colleagues [3] discovered that infectious RSV particles were not released from sarcoma cells during infection with RSV alone. However, if RSV-transformed sarcoma cells were co-infected with a helper avian leucosis virus, Rous-associated virus (RAV), then infectious RSV and RAV progeny were released (as RSV and RAV are antigenicallyunrelated avian C-type retroviruses they could be distinguished). Importantly, it was also shown that the RSV particles produced possessed the RSV genome but the RAV outer 'coat', as determined by serology and cell tropism $[2,3]$. They called these hybrid particles 'pseudotypes'.

A serendipitous property of retroviruses such as RSV is their natural ability to incorporate other cellular proteins, including the envelope proteins of other viruses [46]. The discovery that human immunodeficiency virus 1 (HIV-1; referred to as HIV in this review) effectively incorporates the envelope proteins from human T-lymphotrophic virus $1(\mathrm{HTLV}-1)$ [4] provided evidence that this virus is a tractable platform for making recombinant PVs. Murine leukemia virus (MLV, also referred to as MuLV or Moloney murine leukemia virus, MoMLV) was independently discovered to assemble infectious particles with HTLV-1 envelope proteins [7].

Nomenclature has developed alongside molecular knowledge. The protein nucleocapsid encasing the ribonucleic acid (RNA) genome is now known as the 'core' and the outer membrane of these virus particles, derived from the host cell membrane during viral egress by 'budding', as an 'envelope'. Thus proteins embedded in the membrane become incorporated in the viral envelope and define particle antigenicity and cell tropism. Here, 
the term 'pseudotyped virus' (PV) is defined as an enveloped virus particle comprising a virus capsid/matrix/core surrounded by a cell-derived membrane bearing the foreign virus envelope protein(s) (VEP). The genetic material packaged by a PV does not encode a VEP. Therefore, a PV is capable only of entering and transducing a target cell, initiating nucleic acid replication without producing infectious particles. Depending upon end-user application, PVs have been variously referred to as pseudotypes, pseudo-viruses, pseudo-particles, virus pseudotypes, lenti- or retrovirus vectors, trans-complemented viruses, gene transfer vectors, reporter virus particles and virus-like particles. It is important to note that many of these terms have also been used to describe particles or techniques that do not fit the above definition. The term 'virus envelope protein' is used rather than 'virus glycoproteins' to include non-glycosylated viral surface proteins such as the mature form of the flavivirus $M$ protein and exclude glycosylated non-structural proteins. Furthermore, the distinction between VEP and 'virus surface protein' distinguishes PVs from techniques involving non-enveloped viruses (e.g. adenoassociated virus vectors).

A functional PV can be generated by transfection of a 'producer' cell with three plasmids (Figure 1). The PV 'backbone' is a virus that provides both the core and the recombinant genome packaged by PVs. This combination is essential because genome packaging is mediated by specific interactions between sequences in the genome and the core/matrix/capsid. The most commonly used PV backbones are HIV or MLV retroviruses for which the core expression plasmid encodes the gag and pol genes with no packaging signal. The recombinant genome is typically a reporter gene such as luciferase flanked by retroviral long terminal repeats (LTRs) and a packaging signal $(\psi)$. The third plasmid expresses the open reading frame of the VEP of the virus of interest with appropriate signal peptide. 


\section{Applications of pseudotyped viruses (PVs)}

The flexibility of PVs means that they are suitable for a wide range of applications. A key feature of PVs is that they cannot replicate apart from the reporter gene maintained as the genome; they are therefore widely used at ACDP/BSL 1 or 2 (regardless of the origin of the VEP) and have been particularly valuable in the study of highly pathogenic viruses.

\section{$P V s$ for research and therapeutic agent screening}

PVs offer the ability to rapidly generate key data in the characterization of virus-host interactions. The use of PVs has been of crucial significance in the rapid pace of research into the Middle Eastern Respiratory syndrome (MERS) outbreak [8-11]. During the recent Ebola outbreak, PVs were successfully used in high-throughput screening studies that helped in the identification of potential antivirals and filovirus entry inhibitors [1214] as well as in the study of the viral life cycle and virus receptor interaction [15].

PVs have been used extensively to investigate the entry cascade of hepatitis C virus (HCV) for which, until recently, a robust in vitro cell-culture system did not exist for primary virus isolates. The two glycoproteins of HCV, E1 and E2, have been successfully expressed and incorporated into PVs, initially as modified glycoproteins into VSV backbones [16], then later as unmodified constructs using VSV [17], MLV [6] and HIV [18] backbones. The entry pathway of genetically diverse HCV strains was dissected using these experimental systems, revealing a requirement for an array of receptors [19-23]. Both E1 and E2 are required for assembly of infectious PVs with E2 acting as a chaperone for E1 incorporation, interacting with both E1 and the retroviral core [24]. Using PVs to investigate the effects of specific point mutations on HCV entry also revealed key amino acids involved in receptor interactions [25-27]. However, comparison with authentic HCV revealed that PVs are less tolerant to alteration in vitro. 


\section{PVs for measuring antibodies}

PVs have been used as surrogates of wild-type viruses in sensitive, high throughput neutralization assays (PVNAs), also referred to as pseudotyped particle- (pp-) or pseudotyped virus-based microneutralization assays (pv-MN). For most PVNAs, serial dilutions of sera are incubated with a pre-determined amount of a PV (quantified by the measurement of reporter gene expression) for one hour at $37^{\circ} \mathrm{C}$. A fixed amount of virus-susceptible target cells is then added and reporter gene expression measured after an appropriate incubation period (e.g. 48 hours) [28]. The titer of antibody is typically expressed as the highest dilution of the sample that reduces reporter gene expression by either $50 \%\left(\mathrm{IC}_{50}\right)$ or $90 \%\left(\mathrm{IC}_{90}\right)$ compared to controls [29]. The PVNA is typically sample-sparing. The option to incorporate a number of different reporter genes means that PVs can be adapted to a multiplex serum screening format $[30,31]$.

Comparative serology studies for highly pathogenic avian influenza (HPAI) of the H5 subtype have shown that results from more traditional serological assays including hemagglutination inhibition, micro-neutralization and single radial hemolysis correlate well with those obtained by PVNA [32]. It is thought that a lower density of hemagglutinin (HA) on the surface of influenza PVs compared to wild-type virus means that a sub-set of antibodies are better able to access cross-reactive epitopes on the stalk of the VEP. The PVNA can therefore be used to measure antibodies generated by prototype 'universal vaccines' composed of HA stem fragments. These antibodies cannot be measured by the classical hemagglutination inhibition test as this relies on measuring blocking of antibodies against the receptor-binding site on the globular head of the HA, which is missing $[33,34]$.

PVs have also been widely used to investigate neutralization of HCV entry. The PVNA was first established to test the neutralizing potency of sera [35-37] and monoclonal antibodies [38-42] against diverse strains of HCV. This revealed the existence of 
broadly-neutralizing antibodies generated during natural infection $[43,44]$ and following immunization with vaccines $[45,46]$. Studies using PVs demonstrated that serum contains factors other than antibodies that have the potential to neutralize HCV entry [47-49], while the apolipoprotein components of serum can enhance HCV infectivity and protect against antibody-mediated neutralization [50,51]. Direct comparison of HCV PVs and wild-type HCV viruses revealed that PVs are more resistant to antibody-mediated neutralisation [41], suggesting that PVNA might over-estimate the amounts of antibody required for clinical administration.

Retroviral PVs bearing the HIV-1 glycoproteins have also been used for high throughput PVNA and assessment of vaccine-induced immunity. Comparison of an array of different assays in multiple laboratories found that PVs were generally more sensitive to neutralization than replicating viruses [52,53], confirming previous findings [54]. As such, PVs might not accurately determine the neutralization potency of inhibitors against a single virus strain, but provide a powerful and rapid method for comparing the neutralization sensitivity of many different strains.

PVs as vaccines

The production of neutralizing antibodies is a hallmark of successful vaccination resulting in protection against virus infections (reviewed in [55]). As VEPs are the key targets of neutralizing antibodies, PVs capable of expressing different proteins might be a very useful platform for vaccine design. VSV has been developed as a vaccine for a wide range of viruses, including severe acute respiratory syndrome corona virus (SARS-CoV; [56]), human papillomavirus 16 (HPV-16; [57]), simian immunodeficiency virus (SIV; [58]) and influenza [59]. However, disadvantages with PVs as vaccines include the potential risk of genomic integration (for retrovirus-based PVs; see below) and a lack of sustained antigen production. As a result, greater efforts have been made to develop virus-like particle (VLP)-based vaccines (reviewed in [60]). 


\section{PVs for gene transfer}

The comparative ease with which VEPs can be swapped has been exploited to produce retrovirus delivery vectors for gene transfer where the integration of packaged transgene into the target cell genome enables longer-term gene expression compared with the episomal vectors, typified by many DNA viruses. The first gene therapy vectors were based on retroviruses with their gag, pol and env regions removed and replaced with a therapeutic gene and sometimes a selective marker. During vector production, the gag, pol and env protein products were supplied in trans by suitable stable packaging cell lines. Although the first gene therapy trial employed a retrovirus vector with its cognate envelope protein [61], soon after, heterologous retrovirus envelopes were used, primarily to enhance target cell transduction and thus therapeutic gene expression [62]. One issue with the original C-type retrovirus vectors (e.g. MLV) was that they were only able to transduce dividing cells. To address this issue, researchers turned to the lentiviruses (e.g. HIV), which do not require replicating cells for efficient transduction.

Another issue has been that of insertional mutagenesis as a result of genomic integration of the transfer gene causing activation of oncogenes [63]. Though a rare occurrence, it did manifest itself by producing leukemia in five patients several years after gene therapy for severe combined immunodeficiency [64]. It is believed that the viral control elements situated in the retrovirus LTRs activate host genes. Consequently, selfinactivating vectors have been designed which eliminate these elements [65]. In order to alter the natural cell tropism of transfer vectors, heterologous envelope glycoproteins have been employed with varying degrees of success [66]. VSV-G was used for pseudotyping retrovirus vectors [67] to broaden the range of target cells, tissues and species, and has been widely adopted since. Conversely, pseudotyping provides the means to retarget viral vectors for transduction of particular targets, such as lung, central nervous system, kidney, liver and hematopoietic cells [66]. 


\section{Considerations for developing novel pseudotyped viruses}

Many different viruses have been pseudotyped. However there is no single standardized experimental approach. There are many factors that need to be considered when generating a novel virus pseudotype, taking into account numerous aspects of the virus biology, the intended application and how tractable the virus is to forming PVs. These are expanded upon in the following sections and summarized in Figure 2. The "plug and play" pseudotype construction model is exemplified by influenza PVs assembled using retroviral cores. With a toolkit of 6 plasmids and a streamlined optimization grid for transfection, most strains of influenza are currently amenable to pseudotyping onto retroviral cores [68-70]. Essentially these assembly processes fall broadly into three protocols with the one chosen being dependent on the HA to be pseudotyped and also the downstream application. The simplest system is employed for generating PVs from highly pathogenic avian influenza viruses of the $\mathrm{H} 5$ and $\mathrm{H} 7$ subtypes which possess multi-basic HA cleavage sites. These are ideal when only HAmediated cell entry is required as there will be no neuraminidase (NA) on the released PVs $[71,72]$. Inclusion of a plasmid encoding NA generates particles that more closely mimic their cognate wild-type virus, which is useful for surveillance and vaccine immunogenicity studies (whole virus vaccines). In order to effectively pseudotype HAs that possess a monobasic HA cleavage site (e.g. from seasonal human influenza viruses), a protease must be supplied (as described below).

\section{Viral backbones for pseudotyping}

As previously mentioned, HIV or MLV retroviruses are the most commonly used backbones for PV production. The HIV backbone for PVs has undergone several iterations to improve safety including the deletion of accessory proteins, promoter sequences and the provision of the HIV rev gene on a separate fourth plasmid (reviewed in [73]). Systems are also available whereby the reporter gene is encoded on the gag-pol plasmid reducing it to a two plasmid transfection system. When establishing a novel virus PV 
system it may be relevant to consider which generation of HIV backbone to use as it has been reported that nef co-expression enhanced PV assembly of VEPs from retroviruses, but not non-retroviruses, on the HIV backbone [74]. Two and three plasmid systems, comparable to the lentivirus system, exist for MLV. MLV is non-pathogenic in humans and has fewer accessory proteins compared to HIV. It was the preferred PV backbone prior to development of the second and third generation HIV systems but the two retrovirus backbones are now comparable in terms of safety and ease of use.

Not all VEPs are incorporated efficiently into HIV or MLV backbones [75]; the choice of backbone for pseudotyping a novel virus may be informed by reports of successful systems published for related viruses. The vesicular stomatitis virus (VSV) system, which was originally applied to the study of Ebola virus (EBOV) envelope proteins [76], provides an alternative. VSV is a single-stranded negative sense RNA virus encoding 5 genes that are transcribed that are transcribed to give separate mRNAs, readily allowing substitution of the glycoprotein gene or insertion of additional heterologous genes within the genome. PVs can be generated by combining a recombinant VSV genome, in which the VSV-G gene has been deleted (rVSV- $\Delta \mathrm{G}^{*}$ ) and is replaced with a reporter gene, with an expression plasmid encoding the desired $\operatorname{VEP}(\mathrm{s})$.

Establishment of the rVSV- $\Delta \mathrm{G}^{*}$ system is complex (Figure 3 ). In order to initiate replication of the rVSV- $\Delta \mathrm{G}^{*}$ genome, cells must be transfected with the pVSV- $\Delta \mathrm{G}^{*}$ genome plasmid and plasmids expressing the VSV nucleoprotein $(N)$, phosphoprotein (P) and polymerase protein $(\mathrm{L})$. Furthermore, initial transcription of the VSV- $\Delta \mathrm{G}^{*}$ genome from the plasmid is controlled by the T7 RNA polymerase promoter (T7 pol). T7 pol is commonly provided by one of two methods: infection of the producer cells with a recombinant virus expressing T7 pol (modified vaccinia virus Ankara (MVA)-T7 or fowlpox virus (FPV)-T7) or by using a clone of the BHK-21 cell line stably expressing T7 pol from a plasmid [77]. T7 helper viruses are preferred because they achieve higher levels of T7 pol activity compared to stable cell lines. The addition of a VSV-G expression 
plasmid results in the production of particles encapsidating the VSV- $\Delta \mathrm{G}^{*}$ genome and coated with VSV-G, or VSV-pseudotyped rVSV. Infection of target cells (lacking the T7 pol and the VSV accessory protein expression plasmids) with these PVs leads to efficient replication of the VSV- $\Delta \mathrm{G}^{*}$ genome and production of non-infectious $\Delta$ Env-rVSV. Therefore transfection of cells with a heterologous VEP expression plasmid and subsequent infection with VSV-pseudotyped rVSV particles leads to the production of heterologous VEP-pseudotyped rVSV. However, due to the high efficiency of VSV-G pseudotyping, it is important to assess PV neutralization with antibodies against the heterologous virus envelope and VSV-G to confirm the composition of the PVs. A comprehensive method for the production of VSV-based PVs is given in [78].

\section{Provision of proteases}

Many viruses make use of host cell proteases for the production or release of mature virus particles. Furthermore, protease usage can be a critical determinant of viral tropism [79]. For seasonal human influenza viruses, the requirement for proteasemediated cleavage of the hemagglutinin in order for it to become fusion competent is a well-documented trait [68, 80-82]. However, protease activation is also a well-studied component in the Paramyxoviridae (a family of negative sense single-strand RNA viruses), where the $\mathrm{F}$ protein precursor must be cleaved in order to facilitate maturation of the fusion protein [83], and in the Coronaviridae (a family of positive sense, singlestrand RNA viruses) where proteases can be involved in both cleavage of the spike protein and facilitating release from the host cell [84-86]. Therefore, it may be necessary to supplement PV generation protocols with specific proteases. In many studies it has become common practice to co-transfect a protease-encoding plasmid alongside the other plasmids required for PV production [68, 80, 82, 87]. For influenza, the most commonly used proteases when supplied as a plasmid are HAT and TMPRSS2 [80]. 
It is also possible to induce protease-mediated activation through the addition of purified protease to the culture medium or purified PV preparation. The addition of exogenous tosyl phenylalanyl chloromethyl ketone (TPCK) trypsin has been demonstrated to facilitate activation of SARS-CoV $[88,89]$ MERS-CoV $[10,90]$ and human coronavirus 229E [91]. Exogenous TPCK trypsin is also used for influenza, but an additional step is required in order to deactivate the protease, using commercially available protease inhibitors, prior to inoculation of the PVs onto target cells $[68,80]$.

\section{Signal peptides and transmembrane domains}

Appropriate signal peptides (SPs) and transmembrane domains (TMDs) are a key component of successful PV production as they contribute to sub-cellular targeting and membrane retention of the VEP. It is necessary to target VEPs to the endoplasmic reticulum to facilitate trafficking to sites of assembly. The exact sites of retrovirus budding is yet to be completely defined. The cytoplasmic tails of VEPs have also been identified as important factors [92-94]. Gibbon ape leukemia virus (GaLV) required the cytoplasmic domains of MLV glycoproteins to form PVs on an HIV-1 backbone [95].

\section{VEP alteration}

The diverse structure of VEPs, a characteristic used to divide them into three major classes (I-III), can be the cause of their inefficient incorporation into PVs and consequently poor viral titers. Issues such as localization to the Golgi complex may be overcome by splicing together different sections of heterologous VEPs, to generate chimeric proteins. The structure of a VEP can be crudely broken down into the ecto-, transmembrane and cytoplasmic domains. Ectodomains play the major role in cell binding and antigenicity so any alterations could affect serological and tropism properties of the VEP so this domain should usually be maintained. However, several studies have shown that switching of the cytoplasmic domains is one mechanism by which PV titers 
can be improved $[16,96,97]$. Carpentier et al. conducted a detailed series of experiments to determine if titers of lentiviral PV bearing the rabies virus envelope protein (RABV-G) could be improved by engineering chimeric VEPs [97]. By swapping in the corresponding domains from VSV-G they were able to generate a series of chimeric VEPs and determine efficiency of VEP incorporation into PVs and infectivity. The only chimera that led to an increase in PV titer comprised the RABV-G ecto- and transmembrane domains with the VSV-G cytoplasmic domain. This work has been expanded by Bentley et al. who showed that RABV-G which previously gave no or very low/unusable PV titers could successfully be pseudotyped by swapping the cytoplasmic domain for that of VSV-G [98]. However, it is important to note that there is some variation within the literature about the exact sequence for the VSV cytoplasmic domain $[16,99,100]$.

The reason chimeric VEPs result in better incorporation of VEP and higher PV titer is unclear. It could be due to a stronger interaction with the backbone matrix/capsid protein if the cytoplasmic domain being introduced is shorter as this may reduce steric hindrance. Alternatively, the chimeric VEPs may be trafficked more efficiently to the sites from which the backbone virus naturally buds.

Other modifications to VEPs can boost titers. Measles virus has two envelope proteins, $\mathrm{F}$ and $\mathrm{H}$, and it has been shown that if the full-length wild-type VEPs are used then only very small quantities of infectious PV are produced [101]. However, if both VEPs are truncated, $\mathrm{H} \Delta 24$ and $\mathrm{F} \Delta 30$, levels of incorporation into PV and the PV titer are both markedly higher. 


\section{Optimizing PV titers}

The VSV glycoprotein (VSV-G) produces high titer PVs and is therefore commonly used as a positive control in developing novel PVs. Hepatitis B virus represents the other extreme where existing systems result in very low infectious PV titers [102].

\section{Quantification of PVs obtained}

PV titer is most commonly determined by measuring reporter gene expression in susceptible target cell lines. However, if little or no expression is seen, it may be necessary to conduct further tests. For retrovirus-based PVs this appears to underestimate the number of cells that have undergone genome integration, due to variability of marker expression; PCR has been employed to determine this more precisely [103, 104]. Titration of viral genomic RNA from producer line supernatants conversely overestimates the number of infectious particles due to the presence of defective interfering particles. Titration of HIV-based PV preparations can also be performed by Gag (p24) protein ELISA [105] with infectivity defined as number of infectious units per unit of p24. Lastly, titration of several retroviral vectors based on reverse transcriptase activity via qPCR has recently been reported [106].

Virus particle analysis has historically been conducted via electron microscopy. However, new technologies (e.g. nanoparticle tracking analysis) have enabled rapid quantification of virus particles and determination of particle size [107]. The continued development of such systems may provide vital information on the efficacy of PV production, both in terms of quantity and quality.

If low titers of PV production are demonstrated, there are several measures that can be taken to boost these to more usable levels as described below. On the other hand, if no detectable titers are observed, it may be necessary to change the approach (for example using a different backbone or generating a chimeric VEP). 


\section{Concentration of $P V s$}

Ultracentrifugation combined with a sucrose cushion or gradient can be used to concentrate PVs $[18,108]$. Concentration of PVs can also be performed using polyethylene glycol (PEG)-precipitation. PEG precipitation has advantages over both ultracentrifugation, which requires expensive equipment, and low speed centrifugation, which can be time consuming. Optimization of incubation time and molecular weight and concentration of PEG used will all be required, however numerous commercial kits are available with specific protocols. An optimized method for MLV uses $8.5 \%(\mathrm{w} / \mathrm{v})$ PEG 6000 for 90 minutes at $4{ }^{\circ} \mathrm{C}$ followed by collection of the precipitate by centrifugation at $7,000 \times g$ for 10 minutes $[109,110]$.

\section{Influence of plasmid and codon optimization}

Codon optimization is used to increase the expression of a protein in organisms by increasing translational efficiency. Most amino acids are encoded by more than one codon with each codon recognized by a specific tRNA. Organisms have developed individual preferences for particular codons for a given amino acid (known as 'codon usage bias'). As the efficient generation of PVs requires good levels of VEP expression in the producer cells, codon optimization relevant for the given producer cell line may improve viral titers [111-114].

The plasmids used to encode the $\operatorname{VEP}(\mathrm{s})$ can also greatly influence expression levels and therefore PV titer $[115,116]$. In order to maximize the level of VEP expression, commercially available plasmids with strong promoter elements are used such as pcDNA, pCAGGS or phCMV. Expression in these plasmids is driven by either the human cytomegalovirus major immediate early or beta-actin promoter, two of the strongest promotors that have been identified. As pcDNA- and phCMV-based plasmids are commercially available they negate downstream intellectual property conflicts. 
The methods of producing PVs on both the VSV and retroviral backbones involve transfection of producer cells with multiple plasmids. Establishing successful transfection of plasmids in appropriate ratios appears to be important for successful generation of infectious PVs. Experiments with HIV-based PVs demonstrated that differences in infectivity occur with different amounts of the VEP plasmid [117]. This also occurs for MLV-based PVs, with the amount of VEP plasmid being finely tuned to the species of virus being pseudotyped [118]. Interestingly, maximal expression of VEP did not always correlate with maximal infectivity, suggesting that optimization of the ratio of expression of viral capsid genes to VEP might be important to generating infectious particles.

\section{Use of PV packaging cell lines}

Cell lines stably expressing one or more components of the PV system have been developed to standardize and simplify PV production and reduce transfection costs.

Transfecting cells with a plasmid encoding a lentivirus or retrovirus backbone with functional LTRs but with a deletion for the packaging signal $(\Psi)$ [119] results in 'PV packaging cells' that continually express high levels of the capsid and enzymes required for retrovirus-based PV production. Subsequent transfection of these cells with plasmids encoding a VEP gene and a reporter gene, with $\psi$ signal and LTRs, results in the production of functional PVs. Specific packaging cell lines have also been generated by maintaining episomal replication of a plasmid encoding the backbone gag-pol genes using selection markers [120]. Packaging cell lines have been produced for a range of PV backbones, including HIV, MLV and FeLV, and are available commercially. More recently, a lentivirus packaging cell line was developed specifically to meet clinical approval standards for the generation of PVs for gene therapy by inserting the HIV gag-pol genes into the genome of 293FT cells using Cre recombinase mediated cassette exchange (RMCE) [121]. 
It is well known that VSV-pseudotyped retrovirus PVs result in high levels of reporter gene expression in producer cells due to transduction of the reporter gene at multiple sites in the genome [122]. Therefore, transduction of producer cells with VSVpseudotyped retrovirus PVs packaging the gene encoding the $\operatorname{VEP}(\mathrm{s})$ for a novel virus will generate a cell line with potentially high levels of VEP expression. This may be appropriate for novel PV candidate viruses with poor envelope protein expression levels.

\section{Improved interaction of PVs with target cells}

During development of entry models for $\mathrm{HCV}$, large differences in PV transduction of target cells were observed $[19,117,123]$, in particular PVs representing HCV genotype 3 were associated with lower infectivity ([19]; unpublished results). As a result, some methodologies have used polybrene, or 'spinoculation' to increase observed infectivity $[117,124,125]$.

As a result of their amino acid composition, VEPs are negatively charged. This can limit the initial and sometimes non-specific interaction between the VEP and molecules on the target cell surface [126]. Addition of polybrene (hexadimethrine bromide), a cationic polymer, to the cell culture media (typically at a final concentration of $8 \mu \mathrm{g} / \mathrm{ml}$ ) is thought to reduce the charge repulsion between the negatively charged VEPs and receptors such as sialic acid or increasing virus aggregation [127]. Spinoculation involves centrifuging VPs onto the target cell surface. Both methods have the effect of increasing observed signal, but increase the complexity of the downstream applications.

\section{Conclusions}

The generation of PVs has facilitated progress in research involving highly pathogenic viruses and has been beneficial to research involving viruses for which in vitro culture methods have not been available. Despite the many success stories, pseudotyping of members of some virus families (e.g. the Flaviviridae) has yet to become a routine 
procedure. Even within virus families for which PVs have been successfully generated, not all subtypes of strains can be predictably pseudotyped by the same methods. In summary, there are numerous factors to be taken into consideration when generating PVs. As the field develops, the range of choice of viral backbones and reporter genes is expanding and progress is being made towards the standardization of protocols for consistency, which is essential for some of the main applications of PVs. Novel viruses may pose technical barriers to pseudotyping, but the resultant PVs will provide a powerful tool to dissect aspects of virus binding and entry as well as in the development of antivirals and vaccines. 


\section{References}

1. Rous P. A Sarcoma of the Fowl Transmissible by an Agent Separable from the Tumor Cells. J. Exp. Med. 13(4), 397-411 (1911).

2. Rubin H. Genetic Control of Cellular Susceptibility to Pseudotypes of Rous Sarcoma Virus. Virology 26 270-276 (1965).

3. Hanafusa $\mathrm{H}$, Hanafusa $\mathrm{T}$, Rubin $\mathrm{H}$. The defectiveness of Rous sarcoma virus. Proc. Natl. Acad. Sci. USA 49 572-580 (1963).

4. Landau NR, Page KA, Littman DR. Pseudotyping with human T-cell leukemia virus type I broadens the human immunodeficiency virus host range. J. Virol. 65(1), 162-169 (1991).

5. Page KA, Landau NR, Littman DR. Construction and use of a human immunodeficiency virus vector for analysis of virus infectivity. J. Virol. 64(11), 5270-5276 (1990).

6. Bartosch B, Dubuisson J, Cosset FL. Infectious hepatitis C virus pseudo-particles containing functional E1-E2 envelope protein complexes. J. Exp. Med. 197(5), 633-642 (2003).

7. Vile RG, Schulz TF, Danos OF, Collins MK, Weiss RA. A murine cell line producing HTLV-I pseudotype virions carrying a selectable marker gene. Virology 180(1), 420-424 (1991).

8. Corti D, Zhao J, Pedotti M et al. Prophylactic and postexposure efficacy of a potent human monoclonal antibody against MERS coronavirus. Proc. Natl. Acad. Sci. USA 112(33), 10473-10478 (2015).

9. Perera RA, Wang P, Gomaa MR et al. Seroepidemiology for MERS coronavirus using microneutralisation and pseudoparticle virus neutralisation assays reveal a high prevalence of antibody in dromedary camels in Egypt, June 2013. Euro. Surv. 18(36), pii=20574 (2013).

10. Qian Z, Dominguez SR, Holmes KV. Role of the spike glycoprotein of human Middle East respiratory syndrome coronavirus (MERS-CoV) in virus entry and syncytia formation. PloS one 8(10), e76469 (2013).

11. Zhao G, Du L, Ma C et al. A safe and convenient pseudovirus-based inhibition assay to detect neutralizing antibodies and screen for viral entry inhibitors against the novel human coronavirus MERS-CoV. Virol. J. 10266 (2013).

12. Long J, Wright E, Molesti $\mathrm{E}$ et al. Antiviral therapies against Ebola and other emerging viral diseases using existing medicines that block virus entry [version 2; referees: 2 approved] F1000Research 4, 30 (2015).

13. Cote M, Misasi J, Ren T et al. Small molecule inhibitors reveal Niemann-Pick C1 is essential for Ebola virus infection. Nature 477(7364), 344-348 (2011).

14. Basu A, Mills DM, Mitchell D et al. Novel Small Molecule Entry Inhibitors of Ebola Virus. J. Infect. Dis. 212 Suppl 2, S425-34 (2015).

15. Kuroda M, Fujikura D, Nanbo $A$ et al. Interaction between TIM-1 and NPC1 Is Important for Cellular Entry of Ebola Virus. J. Virol. 89(12), 6481-6493 (2015).

16. Lagging LM, Meyer K, Owens RJ, Ray R. Functional role of hepatitis C virus chimeric glycoproteins in the infectivity of pseudotyped virus. J. Virol. 72(5), 3539-3546 (1998).

17. Tani H, Komoda Y, Matsuo E et al. Replication-competent recombinant vesicular stomatitis virus encoding hepatitis C virus envelope proteins. J. Virol. 81(16), 8601-8612 (2007).

18. Hsu M, Zhang J, Flint $M$ et al. Hepatitis $C$ virus glycoproteins mediate $\mathrm{pH}-$ dependent cell entry of pseudotyped retroviral particles. Proc. Natl. Acad. Sci. USA 100(12), 7271-7276 (2003).

19. Lavillette D, Tarr AW, Voisset $C$ et al. Characterization of host-range and cell entry properties of the major genotypes and subtypes of hepatitis $C$ virus. Hepatology 41(2), 265-274 (2005). 
20. Meertens $L$, Bertaux $C$, Cukierman $L$ et al. The tight junction proteins claudin-1, 6 , and -9 are entry cofactors for hepatitis C virus. J. Virol. 82(7), 3555-3560 (2008).

21. Zheng A, Yuan F, Li Y et al. Claudin- 6 and claudin-9 function as additional coreceptors for hepatitis C virus. J. Virol. 81(22), 12465-12471 (2007).

22. Liu S, Yang W, Shen L, Turner JR, Coyne CB, Wang T. Tight junction proteins claudin-1 and occludin control hepatitis $C$ virus entry and are downregulated during infection to prevent superinfection. J. Virol. 83(4), 2011-2014 (2009).

23. Bartosch B, Vitelli A, Granier $C$ et al. Cell entry of hepatitis $C$ virus requires a set of co-receptors that include the CD81 tetraspanin and the SR-B1 scavenger receptor. J. Biol. Chem. 278(43), 41624-41630 (2003).

24. Sandrin V, Boulanger P, Penin F, Granier C, Cosset FL, Bartosch B. Assembly of functional hepatitis $C$ virus glycoproteins on infectious pseudoparticles occurs intracellularly and requires concomitant incorporation of E1 and E2 glycoproteins. J. Gen. Virol. 86(12), 3189-3199 (2005).

25. Goffard A, Callens N, Bartosch B et al. Role of N-linked glycans in the functions of hepatitis C virus envelope glycoproteins. J. Virol. 79(13), 8400-8409 (2005).

26. Owsianka AM, Timms JM, Tarr AW et al. Identification of conserved residues in the E2 envelope glycoprotein of the hepatitis C virus that are critical for CD81 binding. J. Virol. 80(17), 8695-8704 (2006).

27. Rothwangl KB, Manicassamy B, Uprichard SL, Rong L. Dissecting the role of putative CD81 binding regions of E2 in mediating HCV entry: putative CD81 binding region 1 is not involved in CD81 binding. Virol. J. 546 (2008).

28. Mather S, Scott S, Temperton N, Wright E, King B, Daly J. Current progress with serological assays for exotic emerging/re-emerging viruses. Future Virol. 8(8), 745-755 (2013).

29. Molesti E, Milani A, Terregino C, Cattoli G, Temperton NJ. Comparative Serological Assays for the Study of $\mathrm{H} 5$ and $\mathrm{H} 7$ Avian Influenza Viruses. Influenza Research and Treatment 20139 (2013).

30. Molesti E, Wright E, Terregino C, Rahman R, Cattoli G, Temperton NJ. Multiplex evaluation of influenza neutralizing antibodies with potential applicability to infield serological studies. J. Immunol. Res. 2014457932 (2014).

31. Wright E, Hayman DT, Vaughan A et al. Virus neutralising activity of African fruit bat (Eidolon helvum) sera against emerging lyssaviruses. Virology 408(2), 183189 (2010).

32. Alberini I, Del Tordello E, Fasolo A et al. Pseudoparticle neutralization is a reliable assay to measure immunity and cross-reactivity to H5N1 influenza viruses. Vaccine 27(43), 5998-6003 (2009).

33. Mallajosyula VV, Citron M, Ferrara $\mathrm{F}$ et al. Influenza hemagglutinin stem-fragment immunogen elicits broadly neutralizing antibodies and confers heterologous protection. Proc. Natl. Acad. Sci. USA 111(25), E2514-2523 (2014).

34. Corti D, Voss J, Gamblin SJ et al. A Neutralizing Antibody Selected from Plasma Cells That Binds to Group 1 and Group 2 Influenza A Hemagglutinins. Science 333(6044), 850-856 (2011).

35. Bartosch B, Bukh J, Meunier JC et al. In vitro assay for neutralizing antibody to hepatitis $C$ virus: evidence for broadly conserved neutralization epitopes. Proc. Natl. Acad. Sci. USA 100(24), 14199-14204 (2003).

36. Yu MY, Bartosch B, Zhang $P$ et al. Neutralizing antibodies to hepatitis $C$ virus (HCV) in immune globulins derived from anti-HCV-positive plasma. Proc. Natl. Acad. Sci. USA 101(20), 7705-7710 (2004).

37. Meunier JC, Engle RE, Faulk K et al. Evidence for cross-genotype neutralization of hepatitis $C$ virus pseudo-particles and enhancement of infectivity by apolipoprotein C1. Proc. Natl. Acad. Sci. USA 102(12), 4560-4565 (2005).

38. Owsianka A, Tarr AW, Juttla VS et al. Monoclonal antibody AP33 defines a broadly neutralizing epitope on the hepatitis $C$ virus E2 envelope glycoprotein. J. Virol. 79(17), 11095-11104 (2005). 
39. Johansson DX, Voisset C, Tarr AW et al. Human combinatorial libraries yield rare antibodies that broadly neutralize hepatitis C virus. Proc. Natl. Acad. Sci. USA 104(41), 16269-16274 (2007).

40. Law M, Maruyama $T$, Lewis J et al. Broadly neutralizing antibodies protect against hepatitis C virus quasispecies challenge. Nat. Med. 14(1), 25-27 (2008).

41. Owsianka AM, Tarr AW, Keck ZY et al. Broadly neutralizing human monoclonal antibodies to the hepatitis C virus E2 glycoprotein. J. Gen. Virol. 89(3), 653-659 (2008).

42. Perotti M, Mancini N, Diotti RA et al. Identification of a broadly cross-reacting and neutralizing human monoclonal antibody directed against the hepatitis $C$ virus E2 protein. J. Virol. 82(2), 1047-1052 (2008).

43. Netski DM, Mosbruger T, Depla E et al. Humoral immune response in acute hepatitis C virus infection. Clin Infect Dis 41(5), 667-675 (2005).

44. Pestka JM, Zeisel MB, Blaser E et al. Rapid induction of virus-neutralizing antibodies and viral clearance in a single-source outbreak of hepatitis C. Proc. Natl. Acad. Sci. USA 104(14), 6025-6030 (2007).

45. Wong JA, Bhat $R$, Hockman $D$ et al. Recombinant hepatitis $C$ virus envelope glycoprotein vaccine elicits antibodies targeting multiple epitopes on the envelope glycoproteins associated with broad cross-neutralization. J. Virol. 88(24), 1427814288 (2014).

46. Colombatto P, Brunetto MR, Maina AM et al. HCV E1E2-MF59 vaccine in chronic hepatitis $\mathrm{C}$ patients treated with PEG-IFNalpha2a and Ribavirin: a randomized controlled trial. J. Viral. Hepat. 21(7), 458-465 (2014).

47. Brown KS, Keogh MJ, Owsianka AM et al. Specific interaction of hepatitis C virus glycoproteins with mannan binding lectin inhibits virus entry. Protein Cell 1(7), 664-674 (2010).

48. Hamed MR, Brown RJ, Zothner $\mathrm{C}$ et al. Recombinant human L-ficolin directly neutralizes hepatitis $C$ virus entry. J. Innate. Immun. 6(5), 676-684 (2014).

49. Zhao $Y$, Ren $Y$, Zhang $X$ et al. Ficolin-2 inhibits hepatitis $C$ virus infection, whereas apolipoprotein E3 mediates viral immune escape. J. Immunol. 193(2), 783-796 (2014).

50. Lavillette $D$, Morice $Y$, Germanidis $G$ et al. Human serum facilitates hepatitis $C$ virus infection, and neutralizing responses inversely correlate with viral replication kinetics at the acute phase of hepatitis C virus infection. J. Virol. 79(10), 60236034 (2005).

51. Bankwitz $D$, Vieyres $G$, Hueging $K$ et al. Role of hypervariable region 1 for the interplay of hepatitis $C$ virus with entry factors and lipoproteins. J. Virol. 88(21), 12644-12655 (2014).

52. Heyndrickx L, Heath A, Sheik-Khalil E et al. International network for comparison of HIV neutralization assays: the NeutNet report II. PloS one 7(5), e36438 (2012).

53. Fenyo EM, Heath A, Dispinseri $S$ et al. International network for comparison of HIV neutralization assays: the NeutNet report. PloS one 4(2), e4505 (2009).

54. Louder MK, Sambor A, Chertova E et al. HIV-1 envelope pseudotyped viral vectors and infectious molecular clones expressing the same envelope glycoprotein have a similar neutralization phenotype, but culture in peripheral blood mononuclear cells is associated with decreased neutralization sensitivity. Virology 339(2), 226-238 (2005).

55. Plotkin SA. Correlates of protection induced by vaccination. Clin. Vaccine Immunol. 17(7), 1055-1065 (2010).

56. Kapadia SU, Simon ID, Rose JK. SARS vaccine based on a replication-defective recombinant vesicular stomatitis virus is more potent than one based on a replication-competent vector. Virology 376(1), 165-172 (2008).

57. Liao JB, Publicover J, Rose JK, Dimaio D. Single-dose, therapeutic vaccination of mice with vesicular stomatitis virus expressing human papillomavirus type 16 E7 protein. Clin. Vaccine Immunol. 15(5), 817-824 (2008). 
58. Schell JB, Rose NF, Bahl K et al. Significant protection against high-dose simian immunodeficiency virus challenge conferred by a new prime-boost vaccine regimen. J. Virol. 85(12), 5764-5772 (2011).

59. Roberts A, Kretzschmar E, Perkins AS et al. Vaccination with a recombinant vesicular stomatitis virus expressing an influenza virus hemagglutinin provides complete protection from influenza virus challenge. J. Virol. 72(6), 4704-4711 (1998).

60. Kushnir N, Streatfield SJ, Yusibov V. Virus-like particles as a highly efficient vaccine platform: diversity of targets and production systems and advances in clinical development. Vaccine 31(1), 58-83 (2012).

61. Blaese RM, Culver KW, Miller AD et al. T lymphocyte-directed gene therapy for ADA- SCID: initial trial results after 4 years. Science 270(5235), 475-480 (1995).

62. Onodera M, Nelson DM, Yachie A et al. Development of improved adenosine deaminase retroviral vectors. J. Virol. 72(3), 1769-1774 (1998).

63. Cavazza A, Moiani A, Mavilio F. Mechanisms of retroviral integration and mutagenesis. Hum. Gene Ther. 24(2), 119-131 (2013).

64. Hacein-Bey-Abina S, Von Kalle C, Schmidt $M$ et al. A serious adverse event after successful gene therapy for $\mathrm{X}$-linked severe combined immunodeficiency. N. Engl. J. Med. 348(3), 255-256 (2003).

65. Corrigan-Curay J, Cohen-Haguenauer $\mathrm{O}, \mathrm{O}$ 'reilly $\mathrm{M}$ et al. Challenges in vector and trial design using retroviral vectors for long-term gene correction in hematopoietic stem cell gene therapy. Mol. Ther. 20(6), 1084-1094 (2012).

66. Bischof $D$, Cornetta K. Flexibility in cell targeting by pseudotyping lentiviral vectors. Methods Mol. Biol. 614 53-68 (2010).

67. Naldini $L$, Blomer U, Gallay $P$ et al. In vivo gene delivery and stable transduction of nondividing cells by a lentiviral vector. Science 272(5259), 263-267 (1996).

68. Carnell GW, Ferrara F, Grehan K, Thompson CP, Temperton NJ. Pseudotypebased neutralization assays for influenza: a systematic analysis. Front. Immunol. 6161 (2015).

69. Garcia JM, Lai JCC. Production of influenza pseudotyped lentiviral particles and their use in influenza research and diagnosis: an update. Expert Rev. Anti Infect. Ther. 9(4), 443-455 (2011).

70. Bentley EM, Mather ST, Temperton NJ. The use of pseudotypes to study viruses, virus sero-epidemiology and vaccination. Vaccine 33(26), 2955-2962 (2015).

71. Xiong $X$, Corti $D$, Liu J et al. Structures of complexes formed by H5 influenza hemagglutinin with a potent broadly neutralizing human monoclonal antibody. Proc. Natl. Acad. Sci. USA 112(30), 9430-9435 (2015).

72. Sui J, Hwang WC, Perez $S$ et al. Structural and functional bases for broadspectrum neutralization of avian and human influenza A viruses. Nat. Struct. Mol. Biol. 16(3), 265-273 (2009).

73. Suzuki Y, Suzuki Y. Gene Regulatable Lentiviral Vector System. In: Viral Gene Therapy, Xu K (Ed), Available from: http://www.intechopen.com/books/viralgene-therapy/gene-regulatable-lentiviral-vector-system (2011)

74. Sandrin V, Cosset FL. Intracellular versus cell surface assembly of retroviral pseudotypes is determined by the cellular localization of the viral glycoprotein, its capacity to interact with Gag, and the expression of the Nef protein. J. Biol. Chem. 281(1), 528-542 (2006).

75. Takeuchi Y, Simpson G, Vile RG, Weiss RA, Collins MK. Retroviral pseudotypes produced by rescue of a Moloney murine leukemia virus vector by C-type, but not D-type, retroviruses. Virology 186(2), 792-794 (1992).

76. Takada A, Robison C, Goto $\mathrm{H}$ et al. A system for functional analysis of Ebola $\square$ virus $\square$ glycoprotein. Proc. Natl. Acad. Sci. USA 94(26), 14764-14769 (1997).

77. Buchholz UJ, Finke S, Conzelmann KK. Generation of bovine respiratory syncytial virus (BRSV) from cDNA: BRSV NS2 is not essential for virus replication in tissue culture, and the human RSV leader region acts as a functional BRSV genome promoter. J. Virol. 73(1), 251-259 (1999). 
78. Whitt MA. Generation of VSV pseudotypes using recombinant DeltaG-VSV for studies on virus entry, identification of entry inhibitors, and immune responses to vaccines. J. Virol. Meth. 169(2), 365-374 (2010).

79. Neumann G, Feldmann H, Watanabe S, Lukashevich I, Kawaoka Y. Reverse genetics demonstrates that proteolytic processing of the Ebola virus glycoprotein is not essential for replication in cell culture. J. Virol. 76(1), 406-410 (2002).

80. Ferrara F, Molesti E, Bottcher-Friebertshauser $\mathrm{E}$ et al. The human Transmembrane Protease Serine 2 is necessary for the production of Group 2 influenza A virus pseudotypes. J. Mol. Genet. Med. 7 309-314 (2012).

81. Dring MM, Morrison MH, Mcsharry BP et al. Innate immune genes synergize to predict increased risk of chronic disease in hepatitis $C$ virus infection. Proc. Natl. Acad. Sci. USA 108(14), 5736-5741 (2011).

82. Bottcher E, Matrosovich T, Beyerle M, Klenk HD, Garten W, Matrosovich M. Proteolytic activation of influenza viruses by serine proteases TMPRSS2 and HAT from human airway epithelium. J. Virol. 80(19), 9896-9898 (2006).

83. Jardetzky TS, Lamb RA. Activation of paramyxovirus membrane fusion and virus entry. Curr. Opin. Virol. 5 24-33 (2014).

84. Shirato K, Matsuyama S, Ujike M, Taguchi F. Role of proteases in the release of porcine epidemic diarrhea virus from infected cells. J. Virol. 85(15), 7872-7880 (2011).

85. Belouzard S, Chu VC, Whittaker GR. Activation of the SARS coronavirus spike protein via sequential proteolytic cleavage at two distinct sites. Proc. Natl. Acad. Sci. USA 106(14), 5871-5876 (2009).

86. Kido H, Niwa Y, Beppu Y, Towatari T. Cellular proteases involved in the pathogenicity of enveloped animal viruses, human immunodeficiency virus, influenza virus A and Sendai virus. Adv. Enzyme. Regul. 36 325-347 (1996).

87. Chaipan C, Kobasa D, Bertram S et al. Proteolytic activation of the 1918 influenza virus hemagglutinin. J. Virol. 83(7), 3200-3211 (2009).

88. Shulla A, Heald-Sargent T, Subramanya G, Zhao J, Perlman S, Gallagher T. A transmembrane serine protease is linked to the severe acute respiratory syndrome coronavirus receptor and activates virus entry. J. Virol. 85(2), 873-882 (2011).

89. Simmons G, Rennekamp AJ, Bates P. Proteolysis of SARS-associated coronavirus spike glycoprotein. Adv. Exp. Med. Biol. 581 235-240 (2006).

90. Gierer S, Bertram S, Kaup $\mathrm{F}$ et al. The spike protein of the emerging betacoronavirus EMC uses a novel coronavirus receptor for entry, can be activated by TMPRSS2, and is targeted by neutralizing antibodies. J. Virol. 87(10), 5502-5511 (2013).

91. Kawase M, Shirato K, Matsuyama S, Taguchi F. Protease-mediated entry via the endosome of human coronavirus 229E. J. Virol. 83(2), 712-721 (2009).

92. Robison CS, Whitt MA. The Membrane-Proximal Stem Region of Vesicular Stomatitis Virus G Protein Confers Efficient Virus Assembly. J. Virol. 74(5), 22392246 (2000).

93. Sandrin V, Muriaux D, Darlix JL, Cosset FL. Intracellular trafficking of Gag and Env proteins and their interactions modulate pseudotyping of retroviruses. $J$. Virol. 78(13), 7153-7164 (2004).

94. Murakami T, Freed EO. The long cytoplasmic tail of gp41 is required in a cell typedependent manner for HIV-1 envelope glycoprotein incorporation into virions. Proc. Natl. Acad. Sci. USA 97(1), 343-348 (2000).

95. Stitz J, Buchholz $\mathrm{CJ}$, Engelstadter $\mathrm{M}$ et al. Lentiviral vectors pseudotyped with envelope glycoproteins derived from gibbon ape leukemia virus and murine leukemia virus 10A1. Virology 273(1), 16-20 (2000).

96. Buonocore L, Blight KJ, Rice CM, Rose JK. Characterization of vesicular stomatitis virus recombinants that express and incorporate high levels of hepatitis $C$ virus glycoproteins. J. Virol. 76(14), 6865-6872 (2002). 
97. Carpentier DC, Vevis K, Trabalza A et al. Enhanced pseudotyping efficiency of HIV-1 lentiviral vectors by a rabies/vesicular stomatitis virus chimeric envelope glycoprotein. Gene Ther. 19(7), 761-774 (2012).

98. Bentley EA, R.; Horton, D.; Banyard, A. C.; Wright, E. . Pseudotyped virus-based serology studies show Arctic-like rabies viruses are sensitive to existing vaccines and biologicals. Society of General Microbiology Annual Conference 2015 (2015).

99. Kohl W, Zimmer G, Greiser-Wilke I, Haas L, Moennig V, Herrler G. The surface glycoprotein E2 of bovine viral diarrhoea virus contains an intracellular localization signal. J. Gen. Virol. 85(5), 1101-1111 (2004).

100. Lei Y, Joo KI, Zarzar J, Wong C, Wang P. Targeting lentiviral vector to specific cell types through surface displayed single chain antibody and fusogenic molecule. Virol. J. 735 (2010).

101. Frecha C, Costa C, Negre D et al. Stable transduction of quiescent T cells without induction of cycle progression by a novel lentiviral vector pseudotyped with measles virus glycoproteins. Blood 112(13), 4843-4852 (2008).

102. Sung VM, Lai MM. Murine retroviral pseudotype virus containing hepatitis $B$ virus large and small surface antigens confers specific tropism for primary human hepatocytes: a potential liver-specific targeting system. J. Virol. 76(2), 912-917 (2002).

103. Sastry L, Johnson T, Hobson MJ, Smucker B, Cornetta K. Titering lentiviral vectors: comparison of DNA, RNA and marker expression methods. Gene. Ther. 9(17), 1155-1162 (2002).

104. Lizee G, Aerts JL, Gonzales MI, Chinnasamy N, Morgan RA, Topalian SL. Real-time quantitative reverse transcriptase-polymerase chain reaction as a method for determining lentiviral vector titers and measuring transgene expression. Hum. Gene Ther. 14(6), 497-507 (2003).

105. Logan AC, Nightingale SJ, Haas DL, Cho GJ, Pepper KA, Kohn DB. Factors influencing the titer and infectivity of lentiviral vectors. Hum. Gene Ther. 15(10), 976-988 (2004).

106. Vermeire J, Naessens E, Vanderstraeten $\mathrm{H}$ et al. Quantification of reverse transcriptase activity by real-time PCR as a fast and accurate method for titration of HIV, lenti- and retroviral vectors. PloS one 7(12), e50859 (2012).

107. Heider S, Metzner C. Quantitative real-time single particle analysis of virions. Virology 462-463 199-206 (2014).

108. Burns JC, Friedmann T, Driever W, Burrascano M, Yee JK. Vesicular stomatitis virus $\mathrm{G}$ glycoprotein pseudotyped retroviral vectors: concentration to very high titer and efficient gene transfer into mammalian and nonmammalian cells. Proc. Natl. Acad. Sci. USA 90(17), 8033-8037 (1993).

109. Cepko C. Large-Scale Preparation and Concentration of Retrovirus Stocks. In: Current Protocols in Molecular Biology, John Wiley \& Sons, Inc. (2001).

110. Aboud M, Wolfson M, Hassan Y, Huleihel M. Rapid purification of extracellular and intracellular Moloney murine leukemia virus. Arch. Virol. 71(3), 185-195 (1982).

111. Burgess-Brown NA, Sharma S, Sobott F, Loenarz C, Oppermann U, Gileadi O. Codon optimization can improve expression of human genes in Escherichia coli: A multi-gene study. Protein Express Purif. 59(1), 94-102 (2008).

112. Lanza AM, Curran KA, Rey LG, Alper HS. A condition-specific codon optimization approach for improved heterologous gene expression in Saccharomyces cerevisiae. BMC Syst. Biol. 833 (2014).

113. Stobart CC, Moore ML. RNA virus reverse genetics and vaccine design. Viruses 6(7), 2531-2550 (2014).

114. Jenkins GM, Holmes EC. The extent of codon usage bias in human RNA viruses and its evolutionary origin. Virus Res. 92(1), 1-7 (2003).

115. Simmons G, Reeves JD, Rennekamp AJ, Amberg SM, Piefer AJ, Bates P. Characterization of severe acute respiratory syndrome-associated coronavirus (SARS-CoV) spike glycoprotein-mediated viral entry. Proc. Natl. Acad. Sci. USA 101(12), 4240-4245 (2004). 
116. Jounai N, Okuda K, Kojima $\mathrm{Y}$ et al. Contribution of the rev gene to the immunogenicity of DNA vaccines targeting the envelope glycoprotein of HIV. J. Gene. Med. 5(7), 609-617 (2003).

117. Mckeating JA, Zhang LQ, Logvinoff $C$ et al. Diverse hepatitis $C$ virus glycoproteins mediate viral infection in a CD81-dependent manner. J. Virol. 78(16), 8496-8505 (2004).

118. Bartosch B, Cosset FL. Studying HCV cell entry with HCV pseudoparticles (HCVpp). Methods Mol. Biol. 510 279-293 (2009).

119. Doty RT, Sabo KM, Chen J, Miller AD, Abkowitz JL. An all-feline retroviral packaging system for transduction of human cells. Hum. Gene Ther. 21(8), 10191027 (2010).

120. Miller AD, Garcia JV, Von Suhr N, Lynch CM, Wilson C, Eiden MV. Construction and properties of retrovirus packaging cells based on gibbon ape leukemia virus. J. Virol. 65(5), 2220-2224 (1991).

121. Sanber KS, Knight SB, Stephen SL et al. Construction of stable packaging cell lines for clinical lentiviral vector production. Sci. Rep. 59021 (2015).

122. Vogt B, Roscher S, Abel B et al. Lack of superinfection interference in retroviral vector producer cells. Hum. Gene Ther. 12(4), 359-365 (2001).

123. Tarr AW, Owsianka AM, Szwejk A, Ball JK, Patel AH. Cloning, expression, and functional analysis of patient-derived hepatitis $\mathrm{C}$ virus glycoproteins. Methods Mol. Biol. 379 177-197 (2007).

124. Giang E, Dorner M, Prentoe JC et al. Human broadly neutralizing antibodies to the envelope glycoprotein complex of hepatitis C virus. Proc. Natl. Acad. Sci. USA 109(16), 6205-6210 (2012).

125. Bahnson AB, Dunigan JT, Baysal BE et al. Centrifugal enhancement of retroviral mediated gene transfer. J. Virol. Meth. 54(2-3), 131-143 (1995).

126. Yang YW, Yang JC. Effect of polyionic compounds on the adsorption of polyoma virus. Antiviral Res. 33(1), 33-39 (1996).

127. Davis HE, Rosinski M, Morgan JR, Yarmush ML. Charged polymers modulate retrovirus transduction via membrane charge neutralization and virus aggregation. Biophys. J. 86(2), 1234-1242 (2004). 


\section{Highlighted References}

1. Bartosch B, Dubuisson J, Cosset FL. Infectious hepatitis C virus pseudo-particles containing functional E1-E2 envelope protein complexes. J Exp Med 197(5), 633-642 (2003). This paper was the first description of a tractable experimental system for interrogating the hepatitis $C$ virus entry pathway and the effect of genetic diversity on entry fitness. It also facilitated assessment of the potency of HCV-neutralising antibodies.

2. Ferrara F, Molesti E, Bottcher-Friebertshauser E et al. The human Transmembrane Protease Serine 2 is necessary for the production of Group 2 influenza A virus pseudotypes. J Mol Genet Med 7 309-314 (2012). This is the first report in the literature of the production of pseudotypes for representative strains of all Group 2 influenza viruses. This represents a significant tool for therapeutic screening applications.

3. Whitt MA. Generation of VSV pseudotypes using recombinant DeltaG-VSV for studies on virus entry, identification of entry inhibitors, and immune responses to vaccines. J Virol Methods 169(2), 365-374 (2010). Details a very comprehensive protocol for the establishment of the recombinant VSV system as a backbone for generating PVs. 


\section{Figure legends}

Figure 1. Schematic of the basic three-plasmid approach to generation of a pseudotyped virus with a retroviral core.

Figure 2. Summary diagram of factors to consider when generating a pseudotyped virus expressing a novel viral envelope protein.

Figure 3. Schematic of generation of a pseudotyped virus with a vesicular stomatitis virus (VSV) core. 